\title{
Herding Behavior between Chinese and Hong Kong Stock Market-Based on Shanghai-Hong Kong Stock Connect Policy
}

\author{
Limin He \\ Jinan University, Guangzhou, China \\ Email: azhlm@foxmail.com
}

How to cite this paper: He, L. M. (2020). Herding Behavior between Chinese and Hong Kong Stock Market-Based on Shanghai-Hong Kong Stock Connect Policy. Modern Economy, 11, 829-847. https://doi.org/10.4236/me.2020.114062

Received: February 23, 2020

Accepted: April 13, 2020

Published: April 16, 2020

Copyright $\odot 2020$ by author(s) and Scientific Research Publishing Inc. This work is licensed under the Creative Commons Attribution International License (CC BY 4.0).

http://creativecommons.org/licenses/by/4.0/

\begin{abstract}
This paper investigates herding behavior between Chinese A-share and HK stock market based on Shanghai-Hong Kong Stock Connect. This research innovatively details the difference in herding behavior between two markets bidirectionally. By applying CCK model and quantile regression, we examine herding behavior between Chinese and HK stock market in asymmetric situations from the perspective of net capital flow of Shanghai-Hong Kong Stock Connect. Our findings suggest that the impact of HK share on A share's herding behavior increases after Shanghai-Hong Kong Stock Connect starts trading. To some extent, the direction of net capital flow of Shanghai-Hong Kong Stock Connect acts as a powerful indicator for investors, which skillfully deflects Chinese stock market. Besides, the way in which HK's stock market influences that of Chinese mainland has undergone a transformation.
\end{abstract}

\section{Keywords}

Herding Behavior, Shanghai-Hong Kong Stock Connect, Quantile

Regression, Chinese Stock Market, HK Stock Market

\section{Introduction}

Classical Economic theory assumes rational people and complete information. However, there is asymmetry information and information incompleteness in real financial market. Human cognitive bias and bounded rationality give rise to various economic and financial anomalies. Therefore, understanding investors' decision-making behavior becomes a research concern. As the globalization of capital market, rising uncertainty tends to lead to increased herding behavior and sharp fluctuations of asset prices. This can affect the stabili- 
ty of the financial system (Chiang \& Zheng, 2010).

Herding refers to the tendency of investors' imitating others trading decision. According to the definition of Christie and Huang (1995), herd behavior is a phenomenon that people give up their personal judgment and base their investment decisions on collective behavior in the market, mimicking the investment decisions of others. This can be explained by psychological mechanism. Kameda and Nakanishi (2003) argue that herding behavior depends on the cost of information collection. When the economic cost of information collection and cognition becomes high, investors tend to follow behavior of others in order to save resources. In addition, heuristic is one of the ways in which humans process information (Jiang et al., 2010). Investors treat investment behaviors of others and experts as a source of information. Therefore, when faced with uncertainty, they tend to be consistent with others' trading activity for believing that others' investment information is more efficient and authoritative.

After implementation of Shanghai-Hong Kong Stock Connect, China's stock market has become the world's 2rd largest one in terms of market capitalization and trading volume (in a broad sense, including Shanghai, Shenzhen and Hong Kong stock market). However, Chinese's stock market as an emerging one has some defects such as irrational valuations, excessive volatility and imperfect regulations. Among A-share investors, individual investors account for more than a half, indicating that they are still the investment entities with the greatest influence in the market. These problems further increase the irrationality of investment behavior. Therefore, understanding herd behavior of China's capital market is of great significance for improvement of capital market efficiency and the integration of A stock market and HK equity market.

This study focuses on bidirectional herd behavior between A-share and HK stock market. Specifically, this paper examines the cross-market contagion of herd behavior between the two stock markets before and after the launch of Shanghai-HK Stock Connect. This study innovatively details the difference of cross-market herding behavior between the two closed related markets. In addition, this paper examines the asymmetry effect of the net capital flow direction of the Shanghai-Hong Kong Stock Connect on herding behavior within and between the A-share and $\mathrm{H}$-share markets. Previous studies mainly focus on the herd behavior in individual markets and relatively few studies have explored the cross-market herd effect, especially the bidirectional herd behavior between A-share and Hong Kong stock market. Empirical results of this study add to existing literature and suggest that the impact of HK share on A share's herding behavior increases after Shanghai-Hong Kong Stock Connect starts trading. To some extent, the direction of net capital flow of Shanghai-Hong Kong Stock Connect acts as a powerful indicator for investors. 


\section{Literature Review Ease of Use}

\section{Empirical Studies on Herding Behavior}

Christie and Huang (1995) firstly propose the return dispersion indicators (CSSD, cross-sectional standard deviation of returns) to measure herd behavior in the market.

$$
\begin{gathered}
\operatorname{CSSD}=\sqrt{\frac{\sum\left(r_{i, t}-\bar{r}\right)^{2}}{N-1}} \\
\operatorname{CSSD}=\alpha+\beta_{1} D_{t}^{L}+\beta_{2} D_{t}^{U}+\epsilon_{t}
\end{gathered}
$$

$N$ is the number of stocks in the market, where $r_{i, t}$ is the realized return of stock $\mathrm{i}$ at time $\mathrm{t}$ and $\bar{r}$ is the equally weighted cross-sectional average stock return of all the stocks among the portfolio. CSSD measures the cross-sectional difference between all individual stock return and market yields. $D_{T}^{L}$ and $D_{t}^{U}$ are set as dummy variables. When the market return lies in the extreme lower tail of the distribution, $D_{T}^{L}=1$ otherwise $D_{T}^{L}=0$. Similarly, when the market return lies in the extreme upper value of the distribution, $D_{t}^{U}=1$ otherwise $D_{t}^{U}=0$. Five or one percent in the lower and upper tail of market return distribution is defined to be extreme cases.

Christie and Huang (1995) (henceforth $\mathrm{CH}$ model) suggest that when facing extreme market fluctuation, investors tend to ignore their personal judgment. Thus, their investment behavior tends to be consistent with aggregate market. In this way, volatility of individual stocks and market tends to converge. In extreme cases, the degree of market dispersion equals zero. When investors' investment behavior is rational, market dispersion is proportional to the market return. However, the $\mathrm{CH}$ model can only recognize herd behavior in extreme market conditions, the validity of the identification is limited. In addition, even in extreme market situations, investors may be faced with the same information set and hence have similar decision-making process.

In order to overcome these limitations of $\mathrm{CH}$ model, Chang et al. (2000) (henceforth CCK model) constructs the cross-section absolute deviation of returns indicator (CSAD) to effectively identify the herd behavior in stock market. This model is derived from the capital asset pricing model (CAPM). According to Goyal and Santa-Clara (2003), there is a significant positive relationship between cross-sectional dispersion of individual stock earnings and market return. Hwang and Salmon (2004) provide evidence that when herd behavior occurs, the relationship between return and risk changes in stock market (i.e. the coefficient of CAPM model $\beta$ changes). However, as CCK method assumes that the $\beta$ remain constant over time under CAPM framework. Therefore, Hwang and Salmon (2004) construct the cross-sectional dispersion of beta coefficient indicator (HS model), taking account of dynamic relationship between market return and risk in a volatile market. Compared to CCK model, HS model enables to theoretically distinguish the real and 
pseudo herd effect in stock market. However, it hasn't been used widely due to computational complexity.

After Christie and Huang (1995) firstly proposed CSSD dispersion indicators and Chang et al. (2000) gave a theoretical analysis of testing herd behavior by CSAD dispersion indicators based on CAPM, an increasing amount of literature began to pay attention to herd behavior in global stock markets. One strand of literature investigates herd effect on the institutional level such as behaviors of mutual fund. The other strand of research focuses on the herd behavior on the level of aggregate market. Chiang and Zheng (2010) confirms the existence of herd behavior in developed countries (except for the United States) and Asian markets and further discovers the asymmetry effect of herd behavior in both rising and declining markets. Herding in emerging markets has aroused research interests over the past decade.

Demirer and Kutan (2006) employs the $\mathrm{CH}$ method to study herd behavior of China's stock market from the firm-level and industry-level perspective and found that herd behavior doesn't exist. Subsequently, Tan et al. (2008) provided evidence of herd behavior in China's stock market, using data of 87 dual listed stocks in Chinese A and B-share market from 1994 to 2003. The empirical result of this research is not consistent with Demirer and Kutan (2006). Compared to Tan et al. (2008), Chiang et al. (2010) further expanded the sample range by using data of all A and B-shares ranging from 1996 to 2007 and found that herding exists in both Shanghai and Shenzhen stock market. No evidence of herding was founded with Chinese B-share market, which is not consistent with Tan et al. (2008). In line with methodology of Tan et al. (2008), Lao and Singh (2011) investigate the herding behavior in Chinese and Indian stock markets and suggest that the crowd movement exists in both. Compared to the results of Tan et al. (2008), the magnitude of herd behavior is higher. Yao et al. (2014) investigate herding behavior from both industry-level and other sub-level perspectives by incorporating monthly data of EPS, market-to-book values into CCK model. It is founded that investors exhibit herd behavior in Chinese stock market, particularly in B-share market which is inconsistent with Luo and Schinckus (2015a) and Tan et al. (2008). Its possible explanation is multicollinearity of traditional CCK model.

Although the CCK model (2000) has a solid theoretical basis, the high-level of autocorrelation of CSAD may lead to nonlinear relationship between dispersion indicators $C S A D_{t}$ and equally weighted market return $R_{m, t}$. The two explanatory variables $R_{m}$ and $R_{m}^{2}$ may also exhibit strong multicollinearity. In order to overcome this problem, Yao et al. (2014) modify CCK model by adding the first-order lag of CSAD and an extra term $\left(R_{m, t}-\bar{R}_{m}\right)^{2}$ to the original equation. Luo and Schinckus (2015a) studies herd behavior in asymmetric context and under extreme market conditions. Results suggest that investors' crowd movement of Chinese stock market in the bullish market is more obvious than that in rising market, and herding is more obvious 
in extreme cases.

The existing literature on herd behavior mainly adopts CCK model. However, empirical results of the herding behavior in China's stock market are inconsistent and greatly influenced by the choice of sample period. Moreover, previous studies mainly focus on the herd behavior in individual markets. Although there are established studies on herd behavior in worlds' main stock market, relatively few studies have explored the cross-market herd effect, especially the bidirectional herd behavior between A-share and Hong Kong stock market. Luo and Schinckus (2015b) firstly studied the herding behavior between Chinese and US stocks market, finding that there is no contagion effect of herd behavior between these two countries. For the perspective of macroeconomic environment and policy systems, listed companies in Shanghai \& Shenzhen and Hong Kong stock market are closely linked. The establishment of the Shanghai-Hong Kong Stock Connect and Shenzhen-Hong Kong Stock Connect provides a research perspective. Therefore, it is particularly necessary to study the variation of herd effect between the A-share and the Hong Kong stock market before and after the establishment of the Shanghai-Hong Kong Stock Market.

\section{Policy Background of Shanghai-Hong Kong Stock Connect}

Shanghai-Hong Kong Stock Connect, a stock market interconnection mechanism program was officially launched on November 17, 2014. Prior to its establishment, there were barriers for mainland investors to access eligible shares in the HK stock market due to China's capital control regimes. Shanghai-Hong Kong Stock Connect was jointly issued and approved by the China Securities Regulatory Commission and the Hong Kong Securities and Futures Commission. Under Stock Connect, Stock Exchange of Hong Kong Limited (SEHK) and Shanghai Stock Exchange (SSE) built mutual order-routing connectivity and technical infrastructure to ensure the trading of listed companies in the two markets. The clearing, settlement and nominee arrangements were established by Hong Kong Securities Clearing Company Limited (HKSCC) and China Securities Depository and Clearing Corporation Limited (CSDC). Hong Kong Securities and Future Commission (HKSFC) and China Securities Regulatory (CSRC) were jointly in charge of regulation and supervision. Listed shares in Shanghai Stock market are quoted and traded in RMB, while that in HK stock markets are quoted in HKD and settled in RMB.

Due to the successful implementation of Shanghai-Hong Kong Stock Connect, Shenzhen-Hong Kong Connect was officially launched on December 5, 2016. Its operation mechanism and institutional arrangements were mainly based on the Shanghai-Hong Kong Stock Connect. The establishment of Shenzhen-Hong Kong Stock Connect further deepened the reform and liberalization of China's capital markets. Therefore, in addition to Qualified Foreign Institutional Investors, other foreign investors can trade listed shares 
both in the Shanghai and Shenzhen markets by Stock Connect, while institutional and personal investors in mainland China who hold an aggregate balance of no less than 500,000 in their securities cash accounts can access eligible shares in HK stock market since December 5, 2016. After the launch of Shenzhen-Hong Kong Stock Connect, the A-H stock premium index fluctuated. According to the Wind database, by the end of March 31, 2017, the capital inflow of Shanghai stock market (northbound) has reached 146.4 billion yuan and that of HK stock market (southbound) has reached 371.9 billion yuan through Stock Connect since its establishment. In terms of Shenzhen-Hong Kong Stock Connect, the capital inflow of Shenzhen Stock Connect (northbound) has reached 48.0 billion yuan and that of Hong Kong stock market (southbound) has reached 26.6 billion yuan.

\section{Methodology}

\subsection{Modified CCK Model}

This paper employs CCK model proposed by Chang et al. (2000), using the cross-sectional absolute deviation (CSAD) indicator to detect the herd behavior. According theoretical analysis by Chang et al. (2000), CSAD and equally weighted market return $R_{m, t}$ exhibits a linear relationship within the capital asset pricing model framework (CAPM). When the investors began to give up personal judgment and make similar decisions, individual stock returns and market yields tends to converge and thus dispersion declines. Therefore, the positive linear relationship between the CSAD and market return $R_{m, t}$ does not exist if herding occurs.

$$
\begin{gathered}
R_{m, t}=\frac{1}{N} \sum R_{i} \\
C S A D_{t}=\frac{1}{N} \sum_{i=1}^{N}\left|R_{i, t}-R_{m, t}\right| \\
C S A D_{t}=c+\gamma_{1}\left|R_{m, t}\right|+\gamma_{2}\left(R_{m, t}\right)^{2}+\varepsilon_{t}
\end{gathered}
$$

$N$ denotes the number of stocks in the market, $R_{i, t}$ the return of a stock at time $t$ and $R_{m, t}$ the equally weighted market return at a certain time. If coefficient $\gamma_{2}$ in Equation (3) is significantly negative, it indicates that there is herding in the market. Otherwise herding behavior does not exist in stock market.

To examine cross-market contagion of herd behavior linkage between the A-share and HK stock market, we modifying CCK model proposed by Chang et al. (2000). The modified CCK model is in line with the methodology of Luo and Schinckus (2015a), which is shown as Equation (4) and Equation (5)

$$
\begin{gathered}
C S A D_{a, t}=c+\gamma_{1} R_{a, t}+\gamma_{2}\left|R_{a, t}\right|+\gamma_{3}\left(R_{a, t}\right)^{2}+\gamma_{4} C S A D_{h k, t}+\gamma_{5}\left(R_{h k, m, t}\right)^{2}+\varepsilon_{t} \\
C S A D_{h k, t}=c+\gamma_{1} R_{h k, t}+\gamma_{2}\left|R_{h k, t}\right|+\gamma_{3} R_{h k, t}^{2}+\gamma_{4} C S A D_{a, t}+\gamma_{5}\left(R_{a, m, t}\right)^{2}+\varepsilon_{t}
\end{gathered}
$$


where $C S A D_{h k, t}$ and $R_{h k, m, t}^{2}$ are variables of Hong Kong stock market, while $C S A D_{a, t}$ and $\left(R_{a, t}\right)^{2}$ of Chinese A-share market. For Equation (4), the significant negative coefficient $\gamma_{3}$ indicates that herding occurs in the Chinese A-share market, whereas a significant positive $\gamma_{4}$ a certain extent of dependence of Chinese A-share market over Hong Kong stock market. A significant negative coefficient $\gamma_{5}$ suggests that herding behavior of Chinese A-share market is influenced by Hong Kong stock market. Similarly, the meaning of coefficients for Equation (5) can be deduced in the same manner.

As the launch of the Shanghai-Hong Kong Stock Connect, its net capital flow has become an important market reference for both institutional and individual investors, affecting investors' sentiment. Existing literature shows that there is asymmetry of herd behavior in stock market (Christie \& Huang, 1995; Hwang \& Salmon, 2004; Bekiros et al., 2017). The magnitude of herding amplifies generally in bearish market.

In order to investigate the asymmetry of the herding behavior in the market, we further modify CCK model by adding a dummy variable. The value of dummy variable is set up to the direction of net capital flow of Shanghai-Hong Kong Stock Connect. If net capital flows into Shanghai stock market (northbound), $D=1$; If net capital flows into Hong Kong stock market, $D=0$.

$$
\begin{aligned}
\operatorname{CSAD}_{a, t}= & c+\gamma_{1} D\left|R_{a, t}\right|+\gamma_{2}(1-D)\left|R_{a, t}\right| \\
& +\gamma_{3} D\left(R_{a, t}\right)^{2}+\gamma_{4}(1-D)\left(R_{a, t}\right)^{2}+\varepsilon_{t} \\
C S A D_{h k, t}= & c+\gamma_{1}(1-D)\left|R_{h k, t}\right|+\gamma_{2} D\left|R_{h k, t}\right| \\
& +\gamma_{3}(1-D)\left(R_{h k, t}\right)^{2}+\gamma_{4} D\left(R_{h k, t}\right)^{2}+\varepsilon_{t}
\end{aligned}
$$

In Equation (6), a significant negative $\gamma_{3}$ indicates existing of herding behavior in Chinese A-share market under a northbound net capital flow of Shanghai-Hong Kong Stock Connect (i.e., the net capital flows into Shanghai stock market), otherwise the herd behavior does not exist. A significant negative $\gamma_{4}$ suggests that there is herd behavior in Chinese A-share market under a southbound net capital flow of Shanghai-Hong Kong Stock Connect (i.e., the net capital flows into HK Stock market). Similarly, the meaning of coefficients in Equation (7) can be deduced in a similar manner.

To further investigate the asymmetric cross-market contagion of herding, this paper divides the sample according to the capital flow direction Shanghai-Hong Kong Stock Connect. Equation (8) to Equation (11) is employed to detect the herd behavior under different market conditions.

$$
\begin{aligned}
C S A D_{a, t}^{\text {in }}= & c+\gamma_{1}^{\text {in }} R_{a, t}^{\text {in }}+\gamma_{2}^{\text {in }}\left|R_{a, t}^{\text {in }}\right|+\gamma_{3}^{\text {in }}\left(R_{a, t}^{\text {in }}\right)^{2} \\
& +\gamma_{4} C S A D_{h k, t}^{\text {in }}+\gamma_{5}\left(R_{h k, m, t}^{\text {in }}\right)^{2}+\varepsilon_{t} \\
C S A D_{a, t}^{\text {out }}= & c+\gamma_{1}^{\text {out }} R_{a, t}^{\text {out }}+\gamma_{2}^{\text {out }}\left|R_{a, t}^{\text {out }}\right|+\gamma_{3}^{\text {out }}\left(R_{a, t}^{\text {out }}\right)^{2} \\
& +\gamma_{4} C S A D_{h k, t}^{\text {out }}+\gamma_{5}\left(R_{h k, m, t}^{\text {out }}\right)^{2}+\varepsilon_{t}
\end{aligned}
$$




$$
\begin{aligned}
C S A D_{h k, t}^{\text {in }}= & c+\gamma_{1}^{\text {in }} R_{h k, t}^{\text {in }}+\gamma_{2}^{\text {in }}\left|R_{h k, t}^{\text {in }}\right|+\gamma_{3}^{\text {in }}\left(R_{h k, t}^{\text {in }}\right)^{2} \\
& +\gamma_{4} C S A D_{a, t}^{\text {in }}+\gamma_{5}\left(R_{a, m, t}^{\text {in }}\right)^{2}+\varepsilon_{t} \\
C S A D_{h k, t}^{\text {out }}= & c+\gamma_{1}^{\text {out }} R_{h k, t}^{\text {out }}+\gamma_{2}^{\text {out }}\left|R_{h k, t}^{\text {out }}\right|+\gamma_{3}^{\text {out }}\left(R_{h k, t}^{\text {out }}\right)^{2} \\
& +\gamma_{4} C S A D_{a, t}^{\text {out }}+\gamma_{5}\left(R_{a, m, t}^{\text {out }}\right)^{2}+\varepsilon_{t}
\end{aligned}
$$

$R_{a, t}^{\text {in }}\left(R_{a, t}^{\text {out }}\right)$ denotes the equally weighted market return of A-share market under states of net capital inflow (outflow) through Shanghai-Hong Kong Stock Connect at time t. $R_{h k, t}^{\text {in }}\left(R_{h k, t}^{\text {out }}\right)$ is equally weighted market return in HK stock market. $C S A D_{a, t}^{\text {in }}\left(C S A D_{a, t}^{\text {out }}\right)$ denotes the cross-sectional absolute deviation in Chinese A-share market at time $t$ under states of net capital inflow (outflow) through Shanghai-Hong Kong Stock Connect at time t. $C S A D_{h k, t}^{\text {in }}\left(C S A D_{h k, t}^{\text {out }}\right)$ denotes the dispersion indicator in Hong Kong stock market.

\subsection{Quantile Regression}

Quantile regression model was pioneer by Koenker \& Bassett (1978), which enables to estimate the variability in the effects of a set of explanatory variables $X$ on explained variable $Y$ across the distribution. Therefore, quantile regression enables to investigate the sensitivity of herd behavior under different quantile of stock return dispersion.

Consider a random variable $y$, its right continuous distribution function is $F(y)=P(Y \leq y)$. The $\tau$ quantile of dependent variable $y_{(\tau)}$ is defined as below:

$$
\tau=P\left(y \leq y_{(\tau)}\right)=F\left(y_{(\tau)}\right)
$$

where $P(\cdot)$ denotes the probability and $F\left(y_{(\tau)}\right)$ the cumulative probability distribution function of $y$.

$y_{(\tau)}$ is the inverse function of $F\left(y_{(\tau)}\right)$. For example, if $\tau=0.5$ or $\tau=0.75, y_{(\tau)}$ is the median or $3 / 4$ quantile of $y$. The $\tau$ quantile function of $y$ is defined as follows:

$$
F^{-1}(\tau)=\inf \{y: F(y) \geq \tau\}
$$

Loss function is defined as below, where $I(Z)$ is an indication function and

$$
\rho(u)=u(\tau-I(u<0))
$$

According to Koenker and Bassett (1978), weighted absolute deviation of $\alpha$ can be minimized only when $\alpha=\hat{y}_{(\tau) t}$. Quantile regression can be estimated by weighted least absolute deviation (WLAD):

$$
\begin{aligned}
& \min _{\alpha} E\left[\omega_{t}\left|y_{t}-a\right|\right] \\
& =-(1-\tau) \int_{-\infty}^{a}\left(y_{t}-a\right) \mathrm{d} F(y)+\tau \int_{a}^{\infty}\left(y_{t}-a\right) \mathrm{d} F(y)
\end{aligned}
$$

where $\tau \in(0,1)$ and $\omega_{t}$ is the weight function. 
Assume that the dependent variable $Y$ is a linear expression of a matrix composed of $\mathrm{k}$ independent variables, and the regression expression of the $\tau$ quantile is

$$
\hat{y}_{(\tau) t}=X^{\prime} \hat{\beta}_{(\tau)}
$$

where $X, \beta$ are $k \times 1$ order column vectors, and $\hat{\beta}_{(\tau)}$ is the estimator of the quantile regression coefficient.

For the conditional mean function $E(Y \mid X=x)=X_{i}^{\prime} \beta$, the parameter can be estimated as below

$$
\hat{\beta}=\arg \min _{\beta \subset R^{k}}\left\{\sum_{i=1}^{T} \rho_{\tau}\left(Y_{i}-x_{i}^{\prime} \beta\right)\right\}
$$

Quantile regression estimates parameters by minimizing the weighted absolute error sum. The weight depends on the difference in quantile points. It enables to estimate the relationship between the explanatory variables and the explanatory variables at any particular quantile, which is more flexible than the general least squares estimation, and provides a better method for testing the herd behavior.

\section{Empirical Analysis}

\subsection{Data}

Data of stock return is collected from TongDaxin Stock Trading Database, including closing prices for all listed companies in A-shares and $\mathrm{H}$-shares and covering a period from $2006 / 01 / 05$ to $2017 / 02 / 27$ on a daily basis. TongDaxin is a professional stock trading platform in China, which is adopted by major Chinese securities companies. Stock data can be exported via TongDaxin. We divide the sample period into two segments for comparative analysis: 2006/01/05-2014/11/14 and 2014/11/17-2017/02/27, which represents the sample before and after the launch of the Shanghai-Hong Kong Stock Connect. Both the two sample periods of Chinese A-share market experienced a complete bull to bear transition. Table 1 presents the main statistical characteristics such as mean and standard deviation of dispersion indicator (CSAD) and equally weighted markets return in both A-share and HK stock markets.

\subsection{Results}

\subsubsection{Cross-Market Herd Behavior between $\mathrm{A}$ - and $\mathrm{H}$-Share Markets} Considering the dependent variable (CSAD) in A-shares from 2006/01/05 to 2016/02/27 (Table 2), the coefficients of $\gamma_{3} \quad\left(\gamma_{3}=-0.632\right.$ before launch of Stock Connect, $\gamma_{3}=-5.292$ after launch of Stock Connect and $\gamma_{3}=-2.042$ during whole sample period $)$ and $\gamma_{5}\left(\gamma_{5}=-2.895\right.$ before launch of Stock Connect, $\gamma_{5}=-2.217$ after launch of Stock Connect and $\gamma_{5}=-1.605$ during whole sample period) are significantly negative. It shows that there exists herd behavior before and after the launch of the Shanghai-Hong Kong Stock Connect. And the absolute value of $\gamma_{3}$ in the first period is larger than the second period, which means a greater herd behavior. In addition, $\gamma_{3}$ is neg- 
ative and $\gamma_{5}$ is positive in the whole sample period, which indicating the herd behavior of A-shares is affected by the $\mathrm{H}$-shares, and there was a certain linkage between of the return dispersion in both A- and H-shares. CSAD means the average dispersion between a single stock return and the market equity return.

Table 1. Descriptive statistics of CSAD and equally weighted market returns in A- and H-share markets.

\begin{tabular}{|c|c|c|c|c|}
\hline & CSAD_HK & CSAD_ASHARE & RM_HK & RM_ASHARE \\
\hline Mean & 0.022087 & 0.019374 & -0.000155 & 0.000908 \\
\hline Median & 0.020136 & 0.017648 & 0.001158 & 0.003315 \\
\hline Maximum & 0.118239 & 0.059083 & 0.173052 & 0.10516 \\
\hline Minimum & 0.000695 & 0.004621 & -0.122969 & -0.10339 \\
\hline Std. Dev. & 0.007182 & 0.006905 & 0.013613 & 0.024418 \\
\hline Skewness & 4.772241 & 1.403185 & -0.630357 & -0.850465 \\
\hline Kurtosis & 47.23132 & 5.792905 & 23.4981 & 6.111377 \\
\hline Jarque-Bera & 223,093 & 1708.034 & $45,954.42$ & 1370.023 \\
\hline Probability & 0.0000 & 0.0000 & 0.0000 & 0.0000 \\
\hline $\mathrm{ADF}$ & $-6.597^{* * *}$ & $-4.603^{* * *}$ & $-30.696^{* * *}$ & $-46.506^{* * *}$ \\
\hline Observations & 2615 & 2615 & 2615 & 2615 \\
\hline
\end{tabular}

Source: TongDaxin Stock Trading Database. Note: ${ }^{* * *}$ denotes significance at the level of $0.001,{ }^{* *}$ the level of 0.01 and * the level of 0.05 . CSAD_HK indicates the cross-section absolute dispersion index of HK stock market and CSAD_ASHARE indicates the cross-section absolute dispersion index of A-share market. RM_HK indicates the equally weighted market return of the HK stock market and RM_ASHARE the equally weighted market return of Chinese A-share market.

Table 2. Cross-market herd behavior test between Chinese A-share and HK stock market.

\begin{tabular}{|c|c|c|c|c|c|c|c|c|}
\hline Dependent variable & Time period & $c$ & $\gamma_{1}$ & $\gamma_{2}$ & $\gamma_{3}$ & $\gamma_{4}$ & $\gamma_{5}$ & $R^{2}$ \\
\hline \multirow{2}{*}{ csad_a_whole } & \multirow{2}{*}{$2006 / 01 / 05-2014 / 11 / 14$} & 0.009 & -0.083 & 0.148 & -0.632 & 0.385 & -2.895 & 0.285 \\
\hline & & $17.261^{* * *}$ & $-14.129^{* * *}$ & $7.529^{* * *}$ & $-2.287^{*}$ & $15.743^{* * *}$ & $-8.582^{* * *}$ & \\
\hline \multirow{2}{*}{ csad_a_whole } & \multirow{2}{*}{$2014 / 11 / 17-2017 / 02 / 27$} & -0.001 & -0.109 & 0.392 & -5.292 & 0.866 & -2.217 & 0.541 \\
\hline & & -1.159 & $-12.777^{* * *}$ & $12.008^{* * *}$ & $-13.040^{* * *}$ & $15.599^{* * *}$ & $-9.778^{* * *}$ & \\
\hline \multirow{2}{*}{ csad_a_whole } & \multirow{2}{*}{$2006 / 01 / 05-2017 / 02 / 27$} & 0.009 & -0.085 & 0.226 & -2.042 & 0.386 & -1.605 & 0.296 \\
\hline & & $18.984^{* * *}$ & $-16.910^{* * *}$ & $13.038^{* * *}$ & $-8.664^{* * *}$ & $18.709^{* * *}$ & $-9.510^{* * *}$ & \\
\hline \multirow{2}{*}{ csad_hk_whole } & \multirow{2}{*}{$2006 / 01 / 05-2014 / 11 / 14$} & 0.014 & 0.141 & 0.374 & 4.078 & 0.257 & -0.051 & 0.622 \\
\hline & & $42.487^{* * *}$ & $17.437^{* * *}$ & $18.211^{* * *}$ & $10.823^{* * *}$ & $16.630^{* * *}$ & -0.560 & \\
\hline \multirow{2}{*}{ csad_hk_whole } & \multirow{2}{*}{$2014 / 11 / 17-2017 / 02 / 27$} & 0.012 & 0.068 & 0.294 & 1.056 & 0.288 & 0.190 & 0.834 \\
\hline & & $28.759^{* * *}$ & $6.774^{* * *}$ & $1.999^{*}$ & $9.532^{* * *}$ & $14.498^{* * *}$ & -0.579 & \\
\hline \multirow{2}{*}{ csad_hk_whole } & \multirow{2}{*}{$2006 / 01 / 05-2017 / 02 / 27$} & 0.013 & 0.106 & 0.487 & 0.373 & 0.266 & -0.136 & 0.633 \\
\hline & & $47.602^{* * *}$ & $16.187^{* * *}$ & $33.725^{* * *}$ & $2.251^{*}$ & $20.297^{* * *}$ & -1.869 & \\
\hline
\end{tabular}

The empirical analysis above is based on Equation (4) and Equation (5).

(4): $C S A D_{a_{-} \text {whole }, t}=c+\gamma_{1} R_{a_{-} \text {whole }, t}+\gamma_{2}\left|R_{a_{-} \text {whole }, t}\right|+\gamma_{3}\left(R_{a_{-} \text {whole }, t}\right)^{2}+\gamma_{4} C S A D_{h k_{-} \text {whole }, t}+\gamma_{5}\left(R_{h k_{-} \text {whole }, m, t}\right)^{2}+\varepsilon_{t}$

(5): $C S A D_{h k \text { whole }, t}=c+\gamma_{1} R_{h k \text { whole }, t}+\gamma_{2}\left|R_{h k \text { whole }, t}\right|+\gamma_{3} R_{h k_{-} \text {whole }, t}^{2}+\gamma_{4} C S A D_{a_{\text {w whole }, t}}+\gamma_{5}\left(R_{a_{\text {w whole }, m, t}}\right)^{2}+\varepsilon_{t}$

Note: There are 1867 stocks in HK stock market and 3147 Chinese A-shares market in total. Time period of each empirical test is shown in Table $2 .{ }^{* * *}$ denotes significance at the level of $0.001,{ }^{* *}$ the level of 0.01 and * the level of 0.05 . Shanghai-Hong Kong Stock Connect was officially launched on November 17 , 2014. 
According to Table 3, the results of the quantile-regression between A- and $\mathrm{H}$-shares show that after the launch of the Shanghai-Hong Kong Stock Connect, the absolute value of $\gamma_{5}$ increases as the quantiles $\left(\gamma_{5}=-2.070\right.$ as tau $=0.5, \gamma_{5}=-3.506$ as tau $=0.75$ and $\gamma_{5}=-4.772$ as tau $\left.=0.9\right)$. It means the herd behavior of $\mathrm{A}$-shares herd affected by the $\mathrm{H}$-share would increase with the quantiles.

Table 4 shows that the absolute value of $\gamma_{3}$ increases as the quantiles $\left(\gamma_{3}=-0.983\right.$ as tau $=0.10, \gamma_{3}=-1.408$ as tau $=0.50$ and $\gamma_{3}=-2.210$ as tau $=0.9)$. The absolute value of $\gamma_{5}$ decreases as the quantiles $\left(\gamma_{5}=-3.591\right.$ as $\operatorname{tau}=0.10, \gamma_{5}=-2.648$ as $\operatorname{tau}=0.50$ and $\gamma_{5}=-1.768$ as tau $\left.=0.9\right)$. This indicates that with the increase of the CSAD quantiles, the degree of herd behavior in A-shares increases, while the impact of the $\mathrm{H}$-shares on A-shares decreases. Comparing the whole period and the two sub-period, the capital flow of Shanghai-Hong Kong Stock Connect have a well-leveraged on A-shares investor, as an investment vane. Also, the mode of influence of HK stock market on A-share market has changed.

However, considering the dependent variable (CSAD) in H-shares, $\gamma_{3}$ and $\gamma_{5}$ are significantly positive in the whole sample period (Table 2). It shows that as a relatively mature capital market, there is no herd behavior in $\mathrm{H}$-share market. In addition, assuming that there is herd behavior in $\mathrm{H}$-shares market, which is not affected by A-shares market, while $\gamma_{4}$ is significantly positive, it shows that there is a connection of CSAD between $\mathrm{H}$-shares market and A-shares market $\left(\gamma_{4}=0.385\right.$ before launch of Stock Connect, $\gamma_{4}=0.866$ after launch of Stock Connect and $\gamma_{4}=0.386$ during whole sample period).

Table 3. Quantile regression results of Cross-market herd behavior test between Chinese A-share and HK stock market after launch of Shanghai-Hong Kong Stock Connect.

\begin{tabular}{|c|c|c|c|c|c|c|c|}
\hline & $c$ & $\gamma_{1}$ & $\gamma_{2}$ & $\gamma_{3}$ & $\gamma_{4}$ & $\gamma_{5}$ & $R^{2}$ \\
\hline $\operatorname{tau}=0.10$ & 0.001 & -0.081 & 0.232 & -3.098 & 0.572 & -2.549 & 0.235 \\
\hline t-stat. & 0.664 & $-5.868^{* * *}$ & $6.239^{* * *}$ & $-6.220^{* * *}$ & $5.667^{* * *}$ & $-2.702^{* *}$ & \\
\hline $\operatorname{tau}=0.25$ & 0.001 & -0.108 & 0.294 & -4.165 & 0.655 & -1.649 & 0.279 \\
\hline t-stat. & 0.374 & $-8.686^{* * *}$ & $5.358^{* * *}$ & $-3.730^{* * *}$ & $6.503^{* * *}$ & -0.519 & \\
\hline $\mathrm{tau}=0.50$ & -0.002 & -0.117 & 0.375 & -5.121 & 0.870 & -2.070 & 0.354 \\
\hline t-stat. & -1.506 & $-9.736^{* * *}$ & $9.900^{* * *}$ & $-8.254^{* * *}$ & $12.438^{* * *}$ & $-9.535^{* * *}$ & \\
\hline $\mathrm{tau}=0.75$ & -0.008 & -0.114 & 0.387 & -5.269 & 1.351 & -3.506 & 0.398 \\
\hline t-stat. & $-4.578^{* * *}$ & $-10.229^{* * *}$ & $7.857^{* * *}$ & $-7.964^{* * *}$ & $11.858^{* * *}$ & $-9.674^{* * *}$ & \\
\hline $\mathrm{tau}=0.90$ & -0.011 & -0.091 & 0.348 & -4.516 & 1.694 & -4.772 & 0.384 \\
\hline t-stat. & $-2.024^{*}$ & $-3.353^{* * *}$ & $3.261^{* *}$ & $-3.142^{* *}$ & $5.650^{* * *}$ & $-5.602^{* * *}$ & \\
\hline
\end{tabular}

Note: Sample period is from 2014/11/17 to 2017/02/27. The sample in this test includes all stocks in A and H-share markets. The quantile regression is based on Equation (4).

(4): $C S A D_{a_{-} \text {whole }, t}=c+\gamma_{1} R_{a_{\_} \text {whole }, t}+\gamma_{2}\left|R_{a_{\text {_whole }}, t}\right|+\gamma_{3}\left(R_{a_{\_} \text {whole }, t}\right)^{2}+\gamma_{4} C S A D_{h k_{\_} \text {whole }, t}+\gamma_{5}\left(R_{h k \_ \text {whole, }, m, t}\right)^{2}+\varepsilon_{t}$ 
Table 4. Quantile regression result of cross-market herd behavior test between Chinese A-share and HK stock market during the whole sample period.

\begin{tabular}{|c|c|c|c|c|c|c|c|}
\hline & $c$ & $\gamma_{1}$ & $\gamma_{2}$ & $\gamma_{3}$ & $\gamma_{4}$ & $\gamma_{5}$ & $R^{2}$ \\
\hline $\mathrm{tau}=0.10$ & 0.005 & -0.078 & 0.121 & -0.983 & 0.365 & -3.591 & 0.153 \\
\hline $\mathrm{t}$-stat. & $9.800^{* * *}$ & $-14.115^{* * *}$ & $8.962^{* * *}$ & $-4.978^{* * *}$ & $13.180^{* * *}$ & $-4.744^{* * *}$ & \\
\hline $\operatorname{tau}=0.25$ & 0.004 & -0.088 & 0.131 & -0.958 & 0.465 & -3.390 & 0.199 \\
\hline t-stat. & $7.593^{* * *}$ & $-16.760^{* * *}$ & $9.900^{* * *}$ & $-4.674^{* * *}$ & $14.225^{* * *}$ & $-3.324^{* * *}$ & \\
\hline $\mathrm{tau}=0.50$ & 0.005 & -0.094 & 0.167 & -1.408 & 0.548 & -2.648 & 0.233 \\
\hline t-stat. & $8.030^{* * *}$ & $-19.689^{* * *}$ & $10.712^{* * *}$ & $-6.876^{* * *}$ & $17.714^{* * *}$ & $-6.567^{* * *}$ & \\
\hline $\operatorname{tau}=0.75$ & 0.006 & -0.089 & 0.259 & -2.462 & 0.593 & -1.884 & 0.200 \\
\hline t-stat. & $4.312^{* * *}$ & $-9.830^{* * *}$ & $9.214^{* * *}$ & $-6.168^{* * *}$ & $8.743^{* * *}$ & $-10.725^{* * *}$ & \\
\hline $\operatorname{tau}=0.90$ & 0.012 & -0.096 & 0.248 & -2.210 & 0.546 & -1.768 & 0.148 \\
\hline t-stat. & $3.448^{* * *}$ & $-8.872^{* * *}$ & $3.854^{* * *}$ & $-2.145^{*}$ & $3.278^{* * *}$ & $-3.223^{* *}$ & \\
\hline
\end{tabular}

Note: Sample period is from $2006 / 01 / 05$ to $2017 / 02 / 27$. The sample in this test includes all stocks in A and H-share markets. ${ }^{\star * \star}$ denotes significance at the level of $0.001,{ }^{*}$ the level of 0.01 and ${ }^{\star}$ the level of 0.05 . The quantile regression is based on Equation (4).

$C S A D_{a_{-} \text {whole }, t}=c+\gamma_{1} R_{a_{-} \text {whole }, t}+\gamma_{2}\left|R_{a_{-} \text {whole }, t}\right|+\gamma_{3}\left(R_{a_{-} \text {whole }, t}\right)^{2}+\gamma_{4} C S A D_{h k_{-} \text {whole }, t}+\gamma_{5}\left(R_{h k_{-} \text {whole }, m, t}\right)^{2}+\varepsilon_{t}$

\subsubsection{Cross-Market Herd Behavior for Listed Stocks of Shanghai-Hong Kong Stock Connect}

Compared with the herd behavior of the whole A-shares market, the listed stocks of Shanghai-Hong Kong stock connect is more significant. And compared with the two sample periods before and after the launch of Stock Connect (2006/01/05-2014/11/14 and 2014/11/17-2017/02/27), $\gamma_{3}$ and $\gamma_{5}$ are significantly negative. The absolute value of $\gamma_{5}$ increases from 0.985 to 4.769 , while the absolute value of $\gamma_{3}$ the value increases from 0.725 to 4.665 (Table 5). The result shows the increase effect of herd behavior in A-shares market since the launch of the Shanghai-Hong Kong Stock Connect. In addition, there have no herd behavior in HK stock market. Even with the herd behavior, the $\mathrm{H}$-shares market would not be affected by Chinese A-share market. The quantile-regression results in Table 6 and Table 7 show that, with the increase of the quantiles, the absolute value of $\gamma_{5}$ increases after the launch of the Shanghai-Hong Kong stock connect (in Table 6, $\gamma_{5}=-2.305$ as tau $=0.10$, $\gamma_{5}=-4.852$ as tau $=0.50$ and $\gamma_{5}=-10.392$ as tau $\left.=0.9\right)$. From the entire sample period (2006/01/01-2017/02/27), the value of $\gamma_{5}$ fluctuates in a narrow range, which is consistent with the herd behavior test of A-shares in the previous section. It can be seen that $\gamma_{5}$ fluctuates from -2.611 to -2.189 in Table 7.

\subsubsection{Herd Behavior for Dual-Listed Stocks within Chinese A or H-Share Market}

Comparing the herd behavior for all stocks between A- \& H-shares market (5.1.1) and that for dual-listed stocks in the Shanghai-Hong Kong stock connect, the result in Table 8 report some interesting information. 
For the A-H dual-listed stocks, A-shares market does not show a herd behavior before the launch of the Shanghai-Hong Kong Stock Connect $\left(\gamma_{3}\right.$ is significantly positive). In Table $8, \gamma_{3}$ shows a positive value of 3.120 during the whole sample period from 2006/01/05 to 2014/11/14. From the perspective cross-market herd behavior, the significantly negative $\gamma_{5}$ (-2.496, in Table 8) shows that herding exist between the two markets during the whole sample period. This can be attributed to the fact of large market capitalizations of

Table 5. Quantile regression result of cross-market herd behavior between Chinese A-share and HK stock market for listed stocks of Shanghai-Hong Kong Stock Connect.

\begin{tabular}{ccccccccc}
\hline Dependent Variable & Time & $c$ & $\gamma_{1}$ & $\gamma_{2}$ & $\gamma_{3}$ & $\gamma_{4}$ & $\gamma_{5}$ & $R^{2}$ \\
\hline \multirow{2}{*}{ csad_shconnect } & \multirow{2}{*}{$2006 / 01 / 05-2014 / 11 / 14$} & 0.013 & -0.056 & 0.234 & -0.725 & $\mathbf{0 . 2 6 7}$ & -0.985 & 0.224 \\
& & $23.610^{* * *}$ & $-6.821^{* * *}$ & $8.605^{* * *}$ & $-1.993^{*}$ & $9.390^{* * *}$ & $-3.395^{* * *}$ \\
csad_shconnect & $2014 / 11 / 17-2017 / 02 / 27$ & -0.002 & -0.108 & 0.394 & -4.665 & 1.132 & -4.769 & 0.456 \\
& & -1.650 & $-9.792^{* * *}$ & $9.753^{* * *}$ & $-8.863^{* * *}$ & $12.670^{* * *}$ & $-7.529^{* * *}$ \\
csad_hkconnect & $2006 / 01 / 05-2014 / 11 / 14$ & 0.011 & 0.048 & 0.252 & 2.449 & $\mathbf{0 . 1 7 4}$ & -0.231 & 0.405 \\
& & $27.005^{* * *}$ & $5.239^{* * *}$ & $10.490^{* * *}$ & $6.796^{* * *}$ & $10.086^{* * *}$ & -1.852 \\
csad_hkconnect & $2014 / 11 / 17-2017 / 02 / 27$ & 0.009 & 0.071 & 0.077 & 3.759 & $\mathbf{0 . 2 1 5}$ & 0.252 & 0.755 \\
& & $34.225^{* * *}$ & $9.207^{* * *}$ & $3.693^{* * *}$ & $12.150^{* * *}$ & $15.488^{* * *}$ & $2.98^{* *}$ &
\end{tabular}

Note: The empirical analysis above is based on Equation (4) and Equation (5).

(4): $C S A D_{\text {sh_comrect }, t}=c+\gamma_{1} R_{\text {sh_connect }, t}+\gamma_{2}\left|R_{\text {sh__connect, }, t}\right|+\gamma_{3}\left(R_{\text {sh__onnect }, t}\right)^{2}+\gamma_{4} C S A D_{h k, t}+\gamma_{5}\left(R_{h k, m, t}\right)^{2}+\varepsilon_{t}$

(5): $C S A D_{h k, t}=c+\gamma_{1} R_{h k, t}+\gamma_{2}\left|R_{h k, t}\right|+\gamma_{3} R_{h k, t}^{2}+\gamma_{4} C S A D_{\text {sh_connect, }, t}+\gamma_{5}\left(R_{\text {sh_connect, }, t, t}\right)^{2}+\varepsilon_{t}$

Among the eligible securities of Shanghai-Hong Kong Stock Connect, there are 317 stocks in HK market and 575 stocks in Shanghai market. Time period of each empirical tests is shown in Table 2 . $^{* *}$ denotes significance at the level of 0.001 , $^{* *}$ the level of 0.01 and ${ }^{*}$ the level of 0.05 .

Table 6. Quantile regression result of cross-market herd behavior test between Chinese A-share and HK stock market after the launch of Shanghai-Hong Kong Stock Connect (for listed stocks of Stock Connect).

\begin{tabular}{|c|c|c|c|c|c|c|c|}
\hline & $c$ & $\gamma_{1}$ & $\gamma_{2}$ & $\gamma_{3}$ & $\gamma_{4}$ & $\gamma_{5}$ & $R^{2}$ \\
\hline $\mathrm{tau}=0.10$ & 0.001 & -0.068 & 0.314 & -3.766 & 0.560 & -2.305 & 0.225 \\
\hline t-stat. & 0.683 & $-3.413^{* * *}$ & $7.923^{* * *}$ & $-5.882^{* * *}$ & $7.553^{* * *}$ & $-3.585^{* * *}$ & \\
\hline $\mathrm{tau}=0.25$ & -0.001 & -0.097 & 0.333 & -3.778 & 0.818 & -4.002 & 0.266 \\
\hline t-stat. & -0.617 & $-4.352^{* * *}$ & $7.380^{* * *}$ & $-6.036^{* * *}$ & $6.275^{* * *}$ & -1.329 & \\
\hline $\mathrm{tau}=0.50$ & -0.003 & -0.110 & 0.393 & -4.544 & 1.111 & -4.852 & 0.302 \\
\hline t-stat. & $-2.066^{*}$ & $-9.341^{* * *}$ & $10.175^{* * *}$ & $-8.683^{* * *}$ & $9.223^{* * *}$ & $-8.514^{* * *}$ & \\
\hline $\mathrm{tau}=0.75$ & -0.006 & -0.101 & 0.391 & -4.376 & 1.661 & -7.857 & 0.305 \\
\hline t-stat. & $-2.380^{*}$ & $-3.924^{* * *}$ & $4.656^{* * *}$ & $-2.348^{*}$ & $7.249^{* * *}$ & $-4.478^{* * *}$ & \\
\hline $\mathrm{tau}=0.90$ & -0.011 & -0.118 & 0.307 & -3.233 & 2.383 & -10.392 & 0.313 \\
\hline t-stat. & $-3.098^{* * *}$ & $-6.322^{* * *}$ & $2.385^{*}$ & $-1.960^{*}$ & $7.847^{* * *}$ & $-5.476^{* * *}$ & \\
\hline
\end{tabular}

Note: The sample period is from $2014 / 11 / 17$ to $2017 / 02 / 27$. The sample includes listed stocks of Shanghai-Hong Kong Stock Connect. ${ }^{* * *}$ denotes significance at the level of $0.001{ }^{* *}$ the level of 0.01 and ${ }^{*}$ the level of 0.05 . The quantile regression is based on Equation (4).

(4): $C S A D_{\text {sh_connect }, t}=c+\gamma_{1} R_{\text {sh_connect }, t}+\gamma_{2}\left|R_{\text {sh_connect, } t}\right|+\gamma_{3}\left(R_{\text {sh__oonnect }, t}\right)^{2}+\gamma_{4} C S A D_{h k, t}+\gamma_{5}\left(R_{h k, m, t}\right)^{2}+\varepsilon_{t}$ 
Table 7. Quantile regression result of cross-market herd behavior test between Chinese A-share and HK stock market during whole sample period (for listed stocks of Stock Connect).

\begin{tabular}{|c|c|c|c|c|c|c|c|}
\hline & $c$ & $\gamma_{1}$ & $\gamma_{2}$ & $\gamma_{3}$ & $\gamma_{4}$ & $\gamma_{5}$ & $R^{2}$ \\
\hline $\operatorname{tau}=0.10$ & 0.004 & -0.060 & 0.236 & -2.001 & 0.408 & -2.611 & 0.141 \\
\hline t-stat. & $4.942^{* * *}$ & $-8.051^{* * *}$ & $9.744^{* * *}$ & $-4.644^{* * *}$ & $6.789^{* * *}$ & $-2.009^{*}$ & \\
\hline $\operatorname{tau}=0.25$ & 0.003 & -0.070 & 0.199 & -1.412 & 0.595 & -2.979 & 0.185 \\
\hline t-stat. & $5.386^{* * *}$ & $-11.827^{* * *}$ & $11.263^{* * *}$ & $-5.374^{* * *}$ & $13.717^{* * *}$ & $-4.913^{* * *}$ & \\
\hline $\mathrm{tau}=0.50$ & 0.004 & -0.079 & 0.230 & -1.619 & 0.728 & -2.684 & 0.215 \\
\hline t-stat. & $4.786^{* * *}$ & $-9.529^{* * *}$ & $9.826^{* * *}$ & $-5.310^{* * *}$ & $13.635^{* * *}$ & $-5.010^{* * *}$ & \\
\hline $\mathrm{tau}=0.75$ & 0.006 & -0.093 & 0.287 & -2.000 & 0.837 & -2.973 & 0.175 \\
\hline t-stat. & $4.082^{* * *}$ & $-7.208^{* * *}$ & $6.825^{* * *}$ & $-3.399^{* * *}$ & $9.741^{* * *}$ & $-3.778^{* * *}$ & \\
\hline $\mathrm{tau}=0.90$ & 0.014 & -0.080 & 0.242 & -0.801 & 0.734 & -2.189 & 0.141 \\
\hline t-stat. & $2.867^{* *}$ & $-3.176^{*}$ & $2.004^{*}$ & -0.334 & $2.513^{*}$ & $-2.531^{*}$ & \\
\hline
\end{tabular}

Note: The sample period is from 2006/01/05 to 2017/02/27. ${ }^{* * *}$ denotes significance at the level of $0.001,{ }^{* *}$ the level of 0.01 and ${ }^{*}$ the level of 0.05 . The quantile regression is based on Equation (4).

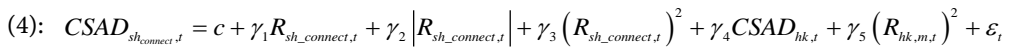

Table 8. Cross-market herd behavior between Chinese A-share and HK stock market for A-H dual listed stocks.

\begin{tabular}{|c|c|c|c|c|c|c|c|c|}
\hline Dependent Variable & Time & $c$ & $\gamma_{1}$ & $\gamma_{2}$ & $\gamma_{3}$ & $\gamma_{4}$ & $\gamma_{5}$ & $R^{2}$ \\
\hline \multirow{2}{*}{ csad_a } & \multirow{2}{*}{$2006 / 01 / 05-2014 / 11 / 14$} & 0.007 & 0.035 & 0.150 & 3.120 & 0.569 & -2.496 & 0.224 \\
\hline & & $6.815^{* * *}$ & $2.74^{* *}$ & $3.652^{* * *}$ & $6.025^{* * *}$ & $9.535^{* * *}$ & $-7.696^{* * *}$ & \\
\hline \multirow{2}{*}{ csad_a } & \multirow{2}{*}{$2014 / 11 / 17-2017 / 02 / 27$} & -0.002 & -0.092 & 0.446 & -4.998 & 0.977 & -1.814 & 0.455 \\
\hline & & -1.7133 & $-6.777^{* * *}$ & $10.307^{* * *}$ & $-8.150^{* * *}$ & $12.925^{* * *}$ & $-4.470^{* * *}$ & \\
\hline \multirow{2}{*}{ csad_h } & \multirow{2}{*}{$2006 / 01 / 05-2014 / 11 / 14$} & 0.012 & 0.045 & 0.199 & 0.910 & 0.081 & -0.109 & 0.405 \\
\hline & & $56.333^{* * *}$ & $8.588^{* * *}$ & $14.205^{* * *}$ & $5.318^{* * *}$ & $11.017^{* * *}$ & -1.204 & \\
\hline \multirow{2}{*}{ csad_h } & \multirow{2}{*}{$2014 / 11 / 17-2017 / 02 / 27$} & 0.009 & 0.051 & 0.045 & 2.616 & 0.250 & -0.075 & 0.673 \\
\hline & & $28.759^{* * *}$ & $6.774^{* * *}$ & $1.999^{*}$ & $9.532^{* * *}$ & $14.498^{* * *}$ & -0.579 & \\
\hline
\end{tabular}

Note: The empirical analysis above is based on Equation (4) and Equation (5).

(4): $C S A D_{a, t}=c+\gamma_{1} R_{a, t}+\gamma_{2}\left|R_{a, t}\right|+\gamma_{3}\left(R_{a, t}\right)^{2}+\gamma_{4} C S A D_{h k, t}+\gamma_{5}\left(R_{h k, m, t}\right)^{2}+\varepsilon_{t}$

(5): $C S A D_{h k, t}=c+\gamma_{1} R_{h k, t}+\gamma_{2}\left|R_{h k, t}\right|+\gamma_{3} R_{h k, t}^{2}+\gamma_{4} C S A D_{a, t}+\gamma_{5}\left(R_{a, m, t}\right)^{2}+\varepsilon_{t}$

There are 94 dual-listed A and H shares. Among the eligible securities of Shanghai-Hong Kong Stock Connect, there are 317 stocks in HK market and 575 stocks in Shanghai market. ${ }^{* *}$ denotes significance at the level of $0.001,{ }^{* *}$ the level of 0.01 and ${ }^{*}$ the level of 0.05 .

dual listed stocks. Over the past decade, investors in Chinese stock market are mainly composed of individuals, who prefer to speculate on stocks with smaller market capitalizations. As a result, investors in A-H dual-listed stock are mainly institutions, who possess more comprehensive information set and relatively rational behaviors. In addition, there is herd behavior within Chinese A-share and between A- \& H-markets after the launch of the Shanghai-Hong Kong Stock Connect ( $\gamma_{3}$ shows a significantly positive value of -4.998 and $\gamma_{5}$ a significantly negative of -1.814 in Table 9), which further confirms the results and analysis of 5.3.1 and 5.3.2. 
Table 9. Test of herd behavior within A-share and HK stock market for dual listed stocks.

\begin{tabular}{|c|c|c|c|c|c|c|c|}
\hline Dependent Variable & Time & $c$ & $\gamma_{1}$ & $\gamma_{2}$ & $\gamma_{3}$ & $\gamma_{4}$ & $R^{2}$ \\
\hline \multirow{2}{*}{ csad_shconnect } & \multirow{2}{*}{$2014 / 11 / 17-2017 / 02 / 27$} & 0.012 & 0.453 & 0.471 & -4.093 & -4.252 & 0.210 \\
\hline & & $22.459^{* * *}$ & $8.061^{* * *}$ & $9.190^{* * *}$ & $-5.451^{* * *}$ & $-6.504^{* * *}$ & \\
\hline \multirow{2}{*}{ csad_hkconnect } & \multirow{2}{*}{$2014 / 11 / 17-2017 / 02 / 27$} & 0.013 & 0.123 & 0.207 & 3.982 & 1.003 & 0.631 \\
\hline & & $58.329^{* * *}$ & $4.746^{* * *}$ & $5.687^{* * *}$ & $10.025^{* * *}$ & 1.239 & \\
\hline \multirow{2}{*}{ csad_a_whole } & \multirow{2}{*}{$2014 / 11 / 17-2017 / 02 / 27$} & 0.015 & 0.380 & 0.452 & -3.497 & -4.442 & 0.201 \\
\hline & & $28.176^{* * *}$ & $7.533^{* * *}$ & $10.074^{* * *}$ & $-5.237^{* * *}$ & $-7.962^{* * *}$ & \\
\hline \multirow{2}{*}{ csad_hk_whole } & \multirow{2}{*}{$2014 / 11 / 17-2017 / 02 / 27$} & 0.017 & 0.362 & 0.415 & 0.812 & -0.914 & 0.749 \\
\hline & & $78.235^{* * *}$ & $14.608^{* * *}$ & $10.184^{* * *}$ & $4.021^{* * *}$ & -1.385 & \\
\hline
\end{tabular}

Note: The empirical analysis above is based on Equation (6) and Equation (7).

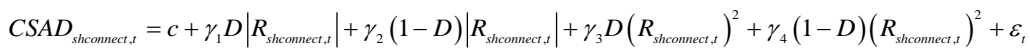

$$
\begin{aligned}
& C S A D_{\text {hkconnect, } t}=c+\gamma_{1}(1-D)\left|R_{\text {hkconnect, } t}\right|+\gamma_{2} D\left|R_{\text {hkcomnect }, t}\right|+\gamma_{3}(1-D)\left(R_{\text {hkconnect, } t}\right)^{2}+\gamma_{4} D\left(R_{\text {hkconnect }, t}\right)^{2}+\varepsilon_{t} \\
& C S A D_{\text {awhole }}=+\gamma_{1} D\left|R_{\text {awhole }, t}\right|+\gamma_{2}(1-D)\left|R_{\text {awhole }, t}\right|+\gamma_{3} D\left(R_{\text {awhole }, t}\right)^{2}+\gamma_{4}(1-D)\left(R_{\text {awhole }, t}\right)^{2}+\varepsilon_{t} \\
& C S A D_{\text {hkwhole }}=+\gamma_{1}(1-D)\left|R_{\text {hkwhole },}\right|+\gamma_{2} D\left|R_{\text {hkwhole }, t}\right|+\gamma_{3}(1-D)\left(R_{\text {hkwhole }, t}\right)^{2}+\gamma_{4} D\left(R_{\text {hkwhole, }}\right)^{2}+\varepsilon_{t}
\end{aligned}
$$

${ }^{* * *}$ denotes significance at the level of $0.001,{ }^{* *}$ the level of 0.01 and ${ }^{*}$ the level of 0.05 . There are 1867 stocks in HK stock market and 3147 Chinese A-shares market in total. Among the eligible securities of Shanghai-Hong Kong Stock Connect, there are 317 stocks in HK market and 575 stocks in Shanghai market. The sample period is shown above. ${ }^{* *}$ denotes significance at the level of $0.001,{ }^{* *}$ the level of 0.01 and ${ }^{*}$ the level of 0.05 . CSAD ${ }_{\text {shconnect, },}$ is computed based on data of listed stocks in Chinese A share stock market and CSAD $D_{\text {awhole }}$ is on data of all stocks in Chinese A share stock market.

According to Table 8, ere is no herd behavior within and between markets. But since the launch of the Shanghai-Hong Kong stock connect, $\gamma_{4}$ increases significantly from 0.569 to 0.977 , which indicates an enhanced linkage between the two stock markets.

\subsubsection{Asymmetry of Herd Behavior within Chinese A or H-Share Market} Table 9 shows that only the A-share market has the herd behavior within the market, while there is no herd behavior within $\mathrm{H}$-share market. For all stocks of A-shares and the Shanghai-Hong Kong stock connect, the absolute value of $\gamma_{4} \quad(D=0$ means the net flow of the Shanghai-Hong Kong stock connect is southbound) is slightly larger than $\gamma_{3}$ ( $D=1$ means the net flow of the Shanghai-Hong Kong stock connect is northbound). In Table 4, the absolute value of $\gamma_{3}$ equals 4.093 and $\gamma_{4}$ equals 4.252. It means that herding of Chinese A-stock market is greater when there is a net capital outflow of Shanghai-Hong Kong Stock Connect. It is in accordance with the theory of loss aversion and expected utility proposed by Tversky \& Kahneman (1979) in the Behavioral Finance. That is, when people face equal gains and losses, losses cause greater mood swings.

\subsubsection{Asymmetry of Cross-Market Herd Behavior}

Table 10 shows that $\gamma_{3}$ and $\gamma_{5}$ are significantly negative, when the fund of Shanghai-Hong Kong stock connect flow out of the A-share market, the herd behavior within the market is relatively strong. In Table 10, the absolute value of $\gamma_{3}$ increases from 4.778 to 5.296 . But the herd behavior between the A- \& $\mathrm{H}$-shares market weakens, the absolute value of $\gamma_{5}$ decreases from 3.977 to 2.072 (Table 10). 
Table 10. Asymmetry of cross-market herd behavior for Chinese-A and H-share stock market.

\begin{tabular}{|c|c|c|c|c|c|c|c|c|}
\hline Dependent Variable & Time & $c$ & $\gamma_{1}$ & $\gamma_{2}$ & $\gamma_{3}$ & $\gamma_{4}$ & $\gamma_{5}$ & $R^{2}$ \\
\hline \multirow[b]{2}{*}{ csad_a_in } & \multirow[b]{2}{*}{$2014 / 11 / 17-2017 / 02 / 27$} & -0.004 & -0.120 & 0.354 & -4.778 & 1.015 & -3.977 & 0.593 \\
\hline & & $-2.085^{*}$ & $-8.841^{* * *}$ & $6.445^{* * *}$ & $-6.903^{* * *}$ & $10.065^{* * *}$ & $-5.886^{* * *}$ & \\
\hline \multirow{2}{*}{ csad_a_out } & \multirow{2}{*}{$2014 / 11 / 17-2017 / 02 / 27$} & 0.000 & -0.102 & 0.392 & -5.296 & 0.837 & -2.072 & 0.531 \\
\hline & & -0.323 & $-9.192^{* * *}$ & $9.417^{* * *}$ & $-10.272^{* * *}$ & $12.374^{* * *}$ & $-7.887^{* * *}$ & \\
\hline \multirow{2}{*}{ csad_hk_in } & \multirow{2}{*}{$2014 / 11 / 17-2017 / 02 / 27$} & 0.012 & 0.084 & 0.359 & 0.666 & 0.298 & 0.025 & 0.871 \\
\hline & & $24.739^{* * *}$ & $8.341^{* * *}$ & $12.561^{* * *}$ & $3.323^{* * *}$ & $12.810^{* * *}$ & 0.205 & \\
\hline \multirow{2}{*}{ csad_hk_out } & \multirow{2}{*}{$2014 / 11 / 17-2017 / 02 / 27$} & 0.013 & 0.040 & 0.197 & 1.565 & 0.286 & 0.452 & 0.720 \\
\hline & & $23.455^{* * *}$ & $2.109^{*}$ & $4.212^{* * *}$ & $2.256^{*}$ & $10.126^{* *}$ & $3.166^{* *}$ & \\
\hline
\end{tabular}

The sample of the above test includes all stocks in A and H-share stock market and the analysis is based on Equation (9) to Equation (11). ${ }^{* * *}$ denotes significance at the level of $0.001,{ }^{* *}$ the level of 0.01 and ${ }^{*}$ the level of 0.05 .
(8) $C S A D_{a, t}^{i n}=c+\gamma_{1}^{i n} R_{a, t}^{i n}+\gamma_{2}^{i n}\left|R_{a, t}^{i n}\right|+\gamma_{3}^{i n}\left(R_{a, t}^{i n}\right)^{2}+\gamma_{4} C S A D_{h k, t}^{i n}+\gamma_{5}\left(R_{h k, m, t}^{i n}\right)^{2}+\varepsilon_{t}$
(9) $C S A D_{a, t}^{\text {out }}=c+\gamma_{1}^{\text {out }} R_{a, t}^{\text {out }}+\gamma_{2}^{\text {out }}\left|R_{a, t}^{\text {out }}\right|+\gamma_{3}^{\text {out }}\left(R_{a, t}^{\text {out }}\right)^{2}+\gamma_{4} C S A D_{h k, t}^{\text {out }}+\gamma_{5}\left(R_{h k, m, t}^{\text {out }}\right)^{2}+\varepsilon_{t}$
(10) $C S A D_{h k, t}^{i n}=c+\gamma_{1}^{i n} R_{h k, t}^{i n}+\gamma_{2}^{i n}\left|R_{h k, t}^{i n}\right|+\gamma_{3}^{i n}\left(R_{h k, t}^{i n}\right)^{2}+\gamma_{4} C S A D_{a, t}^{i n}+\gamma_{5}\left(R_{a, m, t}^{i n}\right)^{2}+\varepsilon_{t}$
(11) $C S A D_{h k, t}^{\text {out }}=c+\gamma_{1}^{\text {out }} R_{h k, t}^{\text {out }}+\gamma_{2}^{\text {out }}\left|R_{h k, t}^{\text {out }}\right|+\gamma_{3}^{\text {out }}\left(R_{h k, t}^{\text {out }}\right)^{2}+\gamma_{4} C S A D_{a, t}^{\text {out }}+\gamma_{5}\left(R_{a, m, t}^{\text {out }}\right)^{2}+\varepsilon_{t}$

Figure 1 describes the net capital inflow of Shanghai-Hong Kong Stock Connect after the launch of Shanghai-Hong Kong Stock Connect. Figure 2 presents the composite index of Shanghai stock market after launch of Shanghai-Hong Kong Stock Connect. Figure 1 and Figure 2 shows, when there are large net inflows for the Shanghai-Hong Kong Stock Connect, the A-share market moves wildly. On this occasion, the fund of Shanghai-Hong Kong stock connect flow out of the A-share market, investors in A-share market may panic. Reduce the attention to the external $\mathrm{H}$-share market, the herd behavior within the market would increase. Luo \& Schinckus (2015a) found that the herd behavior of A-shares in the riskier market was more pronounced than that of the rising market, our study is consistent with the studies of Luo \& Schinckus (2015a).

\section{Conclusion}

In this paper, we expand the CCK model and use quantile-regression model to test herd behavior between $\mathrm{A}-\& \mathrm{H}$-shares market. We make the test from the perspective of the whole market, listed stock in Shanghai-Hong Kong stock connect and A- \& H-shares. The results show that there is a herd behavior before and after the launch of the Shanghai-Hong Kong Stock Connect, and there is a linkage between the two markets in return dispersion. In addition, the results of the quantile-regression show that, since the launch of the Shanghai-Hong Kong stock connect, the influence of HK stock market on herd behavior of Chinese stock market improves with the increase of the quantiles. During whole sample period (2006/01/05-2016/02/27), the influence of HK stock market on herd behavior of Chinese stock market decreases with the increase of the quantiles. Thus, we think the capital flow of Shanghai-Hong Kong stock connect has a well-leveraged effect on A-shares investor, and the mode of influence of HK stock market on Chinese A-shares market has changed. 


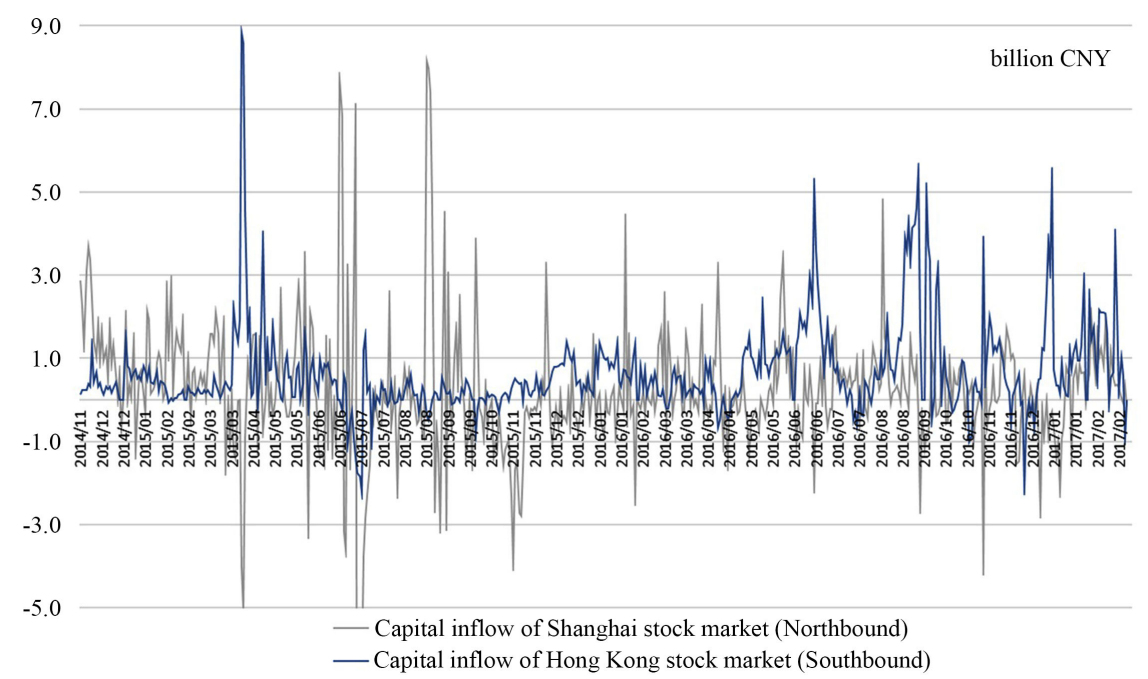

Figure 1. Net capitalinflow of Shanghai-Hong Kong Stock Connect. Source: Wind database.

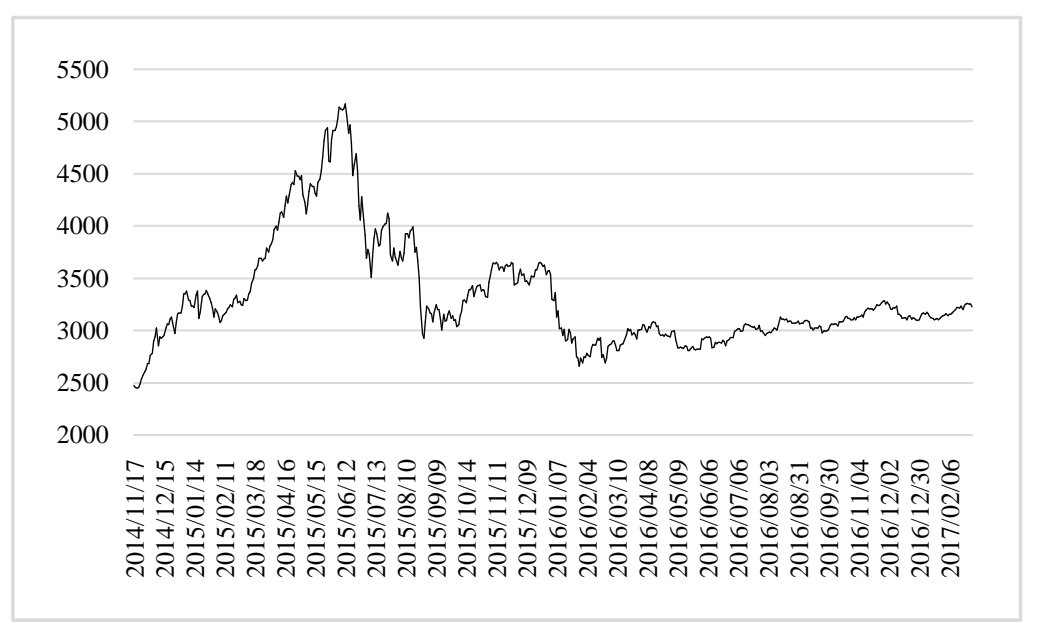

Figure 2. Shanghai SE Composite Index (SSE) after launch of Shanghai-Hong Kong Stock Connect. Source: Wind database.

For the dual-listed stocks in A- \& H-shares market, A-shares market does not show a herd behavior before the launch of the Shanghai-Hong Kong Stock Connect. However, there is a cross-market herd behavior for Chinese A stock market. This can be attributed to the fact that market capitalization of dual-listed stocks is large, and thus investors are mainly composed of institutions.

As a relatively mature capital market, there is no herd behavior in $\mathrm{H}$-share market. Even assuming that there is herd behavior in $\mathrm{H}$-shares market, it is not affected by A-shares market. But there still has a linkage in the yield dispersion.

For the asymmetry test of herd behavior in the market, the results show that the herd behavior of Chinese A-stock market is greater when there is a net capital outflow of Shanghai-Hong Kong Stock Connect. When the fund of Shanghai-Hong Kong Stock Connect flows out of the A-share market, the herd behavior within the market is relatively strong, while the cross-market herd behavior 
between the A- \& H-shares market weakens. It is accordant with the theory of loss aversion.

The herding behavior of Chinese A-share and HK stock market can be extended in several directions. One possibility is to investigate the mechanism of how Shanghai-Hong Kong Stock Connect enhances the herding behavior in Chinese A-stock market, such as the changes of investor structure. Another possibility is to study transition of linkage mechanism of Chinese A-share and Hong Kong stock market after the launch of Stock Connect.

\section{Conflicts of Interest}

The author declares no conflicts of interest regarding the publication of this paper.

\section{References}

Bekiros, S., Jlassi, M., Lucey, B., Naoui, K., \& Uddin, G. S. (2017). Herding Behavior, Market Sentiment and Volatility: Will the Bubble Resume? The North American Journal of Economics and Finance, 42, 107-131. https://doi.org/10.1016/j.najef.2017.07.005

Chang, E. C., Cheng, J. W., \& Khorana, A. (2000). An Examination of Herd Behavior in Equity Markets: An International Perspective. Journal of Banking \& Finance, 24, 1651-1679. https://doi.org/10.1016/S0378-4266(99)00096-5

Chiang, T. C., \& Zheng, D. (2010). An Empirical Analysis of Herd Behavior in Global Stock Markets. Journal of Banking \& Finance, 34, 1911-1921. https://doi.org/10.1016/j.jbankfin.2009.12.014

Chiang, T. C., Li, J., \& Tan, L. (2010). Empirical Investigation of Herding Behavior in Chinese Stock Markets: Evidence from Quantile Regression Analysis. Global Finance Journal, 21, 111-124. https://doi.org/10.1016/j.gfj.2010.03.005

Christie, W. G., \& Huang, R. D. (1995). Following the Pied Piper: Do Individual Returns Herd around the Market? Financial Analysts Journal, 51, 31-37. https://doi.org/10.2469/faj.v51.n4.1918

Demirer, R., \& Kutan, A. M. (2006). Does Herding Behavior Exist in Chinese Stock Markets? Journal of International Financial Markets, Institutions and Money, 16, 123-142. https://doi.org/10.1016/j.intfin.2005.01.002

Goyal, A., \& Santa-Clara, P. (2003). Idiosyncratic Risk Matters! The Journal of Finance, 58, 975-1007. https://doi.org/10.1111/1540-6261.00555

Hwang, S., \& Salmon, M. (2004). Market Stress and Herding. Journal of Empirical Finance, 11, 585-616. https://doi.org/10.1016/j.jempfin.2004.04.003

Jiang, D., Xu, F. M., Chen, X. L., Liu, T. F., \& Zhang, J. W. (2010). The Psychological Mechanism and Influence Factors of Herd Behavior of Investors in the Capital Market. Advances in Psychological Science, 18, 810-818.

Kameda, T., \& Nakanishi, D. (2003). Does Social/Cultural Learning Increase Human Adaptability? Rogers's Question Revisited. Evolution and Human Behavior, 24, 242-260. https://doi.org/10.1016/S1090-5138(03)00015-1

Koenker, R., \& Bassett Jr., G. (1978). Regression Quantiles. Econometrica: Journal of the Econometric Society, 46, 33-50. https://doi.org/10.2307/1913643

Lao, P., \& Singh, H. (2011). Herding Behaviour in the Chinese and Indian Stock Markets. Journal of Asian Economics, 22, 495-506. https://doi.org/10.1016/j.asieco.2011.08.001 
Luo, Z., \& Schinckus, C. (2015a). Herding Behaviour in Asymmetric and Extreme Situations: The Case of China. Applied Economics Letters, 22, 869-873.

https://doi.org/10.1080/13504851.2014.985363

Luo, Z., \& Schinckus, C. (2015b). The Influence of the US Market on Herding Behaviour in China. Applied Economics Letters, 22, 1055-1058.

https://doi.org/10.1080/13504851.2014.997920

Tan, L., Chiang, T. C., Mason, J. R., \& Nelling, E. (2008). Herding Behavior in Chinese Stock Markets: An Examination of A and B Shares. Pacific-Basin Finance Journal, 16, 61-77. https://doi.org/10.1016/j.pacfin.2007.04.004

Tversky, A., \& Kahneman, D. (1979). Prospect Theory: An Analysis of Decision under Risk. Econometrica, 47, 263-291. https://doi.org/10.2307/1914185

Yao, J., Ma, C., \& He, W. P. (2014). Investor Herding Behaviour of Chinese Stock Market. International Review of Economics \& Finance, 29, 12-29.

https://doi.org/10.1016/j.iref.2013.03.002 